\title{
Pronunciamiento sobre convocatoria de la Unión Europea a una reunión de donantes internacionales para apoyar a los países de acogida de emigrantes y refugiados de Venezuela
}

\section{Pronunciamiento SPDI $\mathbf{N}^{\circ}$ 003-2020}

Habiendo tomado conocimiento de la convocatoria realizada por la Unión Europea y el Gobierno de España a una reunión de donantes internacionales para apoyar a los países de acogida de emigrantes y refugiados venezolanos, a realizarse el próximo 26 de mayo, la Sociedad Peruana de Derecho Internacional expresa:

1. Su reconocimiento, felicitación y pleno apoyo a tan acertada iniciativa, que servirá tanto para comprometer apoyos financieros que posibiliten a los países de acogida, dentro de los que se encuentra significativamente el Perú, mejorar la calidad de las atenciones que brinda a los emigrantes y refugiados de Venezuela radicados en sus jurisdicciones; así como para sensibilizar más a la comunidad internacional ante el drama humanitario que afecta a alrededor de 5 millones y medio de ciudadanos de esta nación hermana. Resulta evidente que la magnitud de la diáspora venezolana desborda las responsabilidades y capacidades de los países de acogida, haciendo indispensable forjar una respuesta multilateral. En el caso específico del Perú, la iniciativa de la Unión Europea y del Gobierno de España permitirá contar con mayores y mejores recursos para enfrentar eficazmente los desafíos que plantea su solidaria acogida de casi un millón de emigrantes y refugiados de Venezuela.

2. Su invocación para que la reunión de donantes convocada por la Unión Europea y el Gobierno de España sea el punto de partida para promover una estrategia internacional concertada de atención humanitaria y de desarrollo en favor de los emigrantes y refugiados de Venezuela, así como de las comunidades anfitrionas en los países de acogida, a efectos de crear condiciones de inserción compatibles con la dignidad humana, la sostenibilidad, y la valorización del potencial productivo de esas personas.

3. Su propuesta sobre la necesidad urgente de convocar a una conferencia internacional para formular tal estrategia y sus respectivos programas de acción para promover la inserción social y productiva de emigrantes y refugiados venezolanos radicados en los países 
vecinos. Tal estrategia debiera poner en valor las enseñanzas adquiridas en el contexto regional, particularmente las del proceso generado por la Conferencia Internacional sobre Refugiados Centroamericanos (CIREFCA), realizada en mayo de 1989.

4. Su recomendación que, basada en las mejores prácticas internacionales, tal estrategia debiera contemplar acciones coordinadas entre las dimensiones humanitarias y de desarrollo, en favor de la diáspora venezolana en los países de acogida vecinos. Esto implica, entre otros aspectos: (a) crear condiciones para la total formalización de la situación migratoria de todos los emigrantes y refugiados venezolanos; (b) brindarles asistencia legal tanto para regularizar su situación migratoria como para garantizar la plena vigencia de sus derechos en los países de acogida, previniendo en particular situaciones de explotación laboral y de tráfico de personas; (c) promover la generación de capacidades para su empleabilidad y de apoyo para la ejecución de emprendimientos empresariales; (d) establecer fórmulas de compensación en favor de las comunidades e instituciones de acogida que les brindan servicios básicos; y, (e) la realización de campañas de sensibilización de las poblaciones locales y de los decisores en los países de acogida, para contrarrestar manifestaciones xenófobas.

5. Su convicción que la magnitud del drama humanitario generado por la diáspora venezolana requiere adoptar fórmulas innovadoras para darle atención. Una estrategia de la naturaleza que proponemos requerirá cuantiosas inversiones, que debieran ser principalmente financiadas por organismos financieros multilaterales, imputando los fondos asignados como crédito a ser reembolsado por el Estado de Venezuela. Desde el punto de vista del Derecho Internacional, esta propuesta es novedosa y plenamente legítima, considerando que el éxodo de alrededor de 5 millones y medio de ciudadanos venezolanos ha sido generado por las singulares condiciones de ejercicio del poder político en ese país.

6. Su inquebrantable convicción que Venezuela tiene que recuperar plenas condiciones de gobernabilidad democrática y de estabilidad política, siendo esta una tarea que en lo fundamental recae en la ciudadanía de este país hermano; sin perjuicio de lo cual la comunidad internacional tiene el deber de responder frente al drama humanitario de la diáspora venezolana, apoyando a los países de acogida vecinos para que puedan brindarles condiciones de inserción compatibles con la dignidad humana, la sostenibilidad, y la valorización del potencial productivo de esas personas. 
Revista Peruana de Derecho Internacional

Tomo LXX Mayo-Agosto $2020 \mathcal{N}^{\circ} 165$, pp. 367-369. ISSN: 2663-0222

Recepción: 30/05/2020 Aceptación: 07/07/2020

Lima, 18 de mayo de 2020 